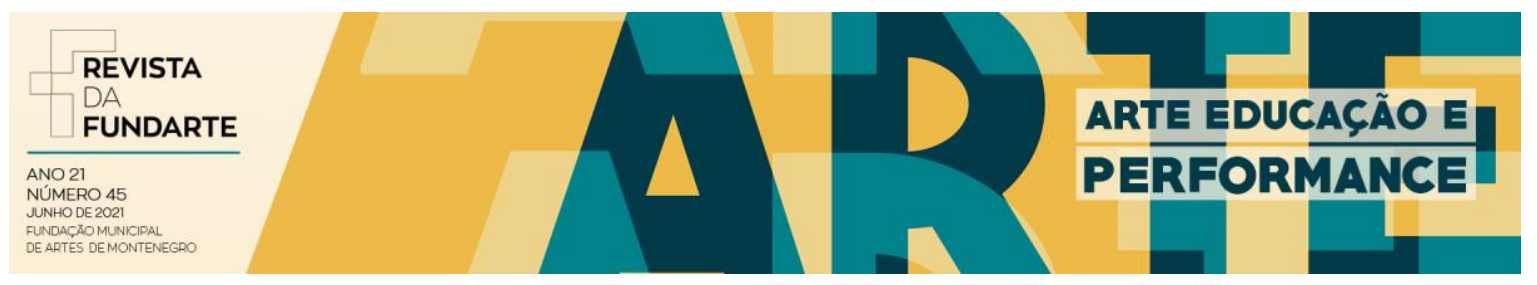

O APRENDIZADO INFORMAL DA DANÇA K-POP: JUVENTUDE, TRANSCULTURALIDADE E PERFORMANCES DE GÊNERO

\author{
Giuliano Souza Andreoli \\ Braçi Fernandes
}

DOI: $10.19179 / 2319-0868 / 814$

ANDREOLI, Giuliano Souza; FERNANDES, Braçi. O aprendizado informal da dança k-pop: juventude, transculturalidade e performances de gênero. Revista da FUNDARTE. Montenegro, p.01-21, ano 21, no 45, junho de 2021.

Disponível em: http://.seer.fundarte.rs.gov.br/index.php/revistadafundarte/index> 30 de junho de 2021. 


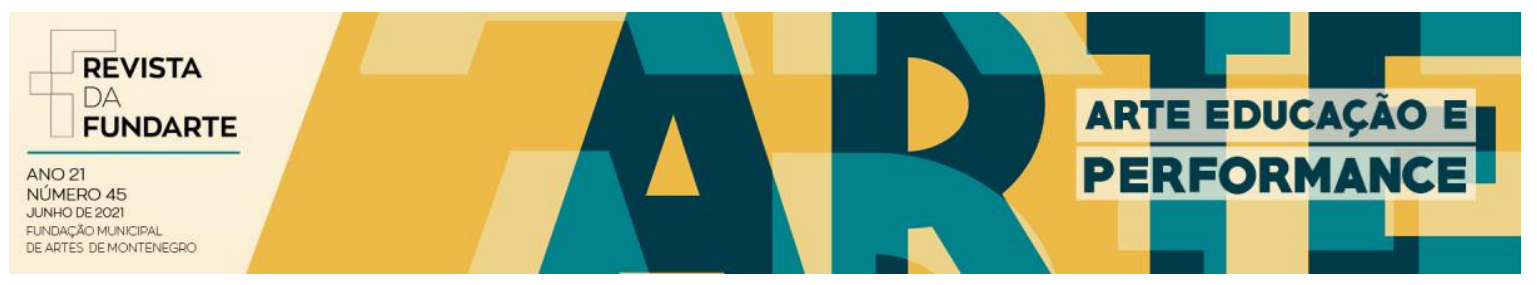

\title{
O APRENDIZADO INFORMAL DA DANÇA K-POP: JUVENTUDE, TRANSCULTURALIDADE E PERFORMANCES DE GÊNERO
}

\author{
Giuliano Souza Andreoli ${ }^{1}$ \\ Braçi Fernandes ${ }^{2}$
}

\begin{abstract}
Resumo: O objetivo deste artigo, apoiado em pesquisa de campo de inspiração etnográfica, é investigar o perfil dos grupos de Covers de dança K-pop na cidade de Porto Alegre. Buscou-se compreender como os produtos da Indústria Cultural afetam os processos de aprendizagem e criação em dança. Os dispositivos metodológicos construídos foram observações participantes, acompanhando ensaios e eventos de grupos e coletivos culturais. O estudo tomou como base teórica autores como Martín-Barbero, Mafessoli and Butler, para discutir temas como cultura pop, juventude, identidade, neotribos e performances de gênero. Concluímos que os produtos da indústria K-pop potencializam processos informais de aprendizagem e a sociabilidade entre jovens em suas diferenças de gênero, à margem da cultura hegemônica de dança.
\end{abstract}

Palavras-chave: Danças midiáticas; K-pop; Juventude; Gênero.

\section{INFORMAL LEARNING OF K-POP DANCE: YOUTH, TRANSCULTURALITY AND GENDER PERFORMANCES}

\begin{abstract}
The aim of this paper, supported by field research of ethnographic inspiration, is to investigate the profile of the K-pop cover dance groups in the city of Porto Alegre. It was intended to comprehended how the products of the Cultural Industry affect the process of learning and creation in dance. The methodological strategies developed were participant observation, accompanying practices and events among cultural groups and collectives. The study took as theoretic base authors like Martín-Barbero, Mafessoli and Butler, to discuss pop culture, identity, neotribes and gender performances. We concluded that the K-pop products can enhance informal learning process and
\end{abstract}

1 Possui graduação em Educação Física (UFRGS), Especialização em Pedagogias do Corpo (UFRGS), e Mestrado em Educação (UFRGS). Atua na área de Teoria da Dança, com ênfase na relação entre Dança e Educação, Dança e Ciências Humanas (Antropologia, Sociologia, História, Estudos Culturais, Estudos de Gênero). É professor do Curso de Graduação em Dança: Licenciatura da Universidade Estadual do Rio Grande do Sul (UERGS). Atua principalmente nas disciplinas: Teoria da Dança, Dança e Cultura I e II, História da Dança I e II, Educação e Pluralidade Cultural e Técnicas corporais Circenses.

${ }^{2}$ Braçi Fernandes é graduando em Dança: Licenciatura pela Universidade Estadual do Rio Grande do Sul/ UERGS. Foi Bolsista pelo Programa Institucional de Bolsas de Iniciação a Docência. É integrante do grupo Dharma DT, onde atua como diretor e coreógrafo. Atua como professor e coordenador de projetos educacionais na educação fundamental

ANDREOLI, Giuliano Souza; FERNANDES, Braçi. O aprendizado informal da dança k-pop: juventude, transculturalidade e performances de gênero. Revista da FUNDARTE. Montenegro, p.01-21, ano 21, no 45, junho de 2021.

Disponível em: http://.seer.fundarte.rs.gov.br/index.php/revistadafundarte/index> 30 de junho de 2021. 


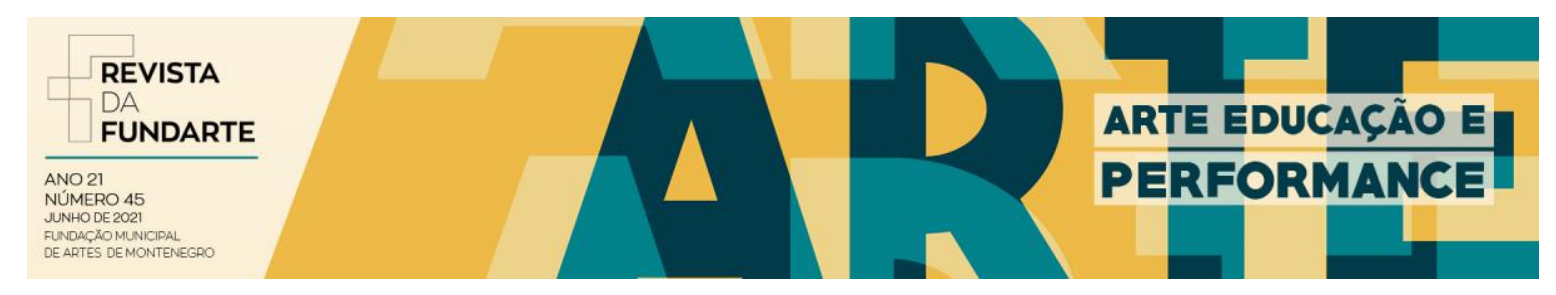

sociability among young people in their gender differences, on the margins of hegemonic culture of dance.

Keywords: Media dances; K-pop; Youth; Gender.

Nesta era globalizada, com a propagação rápida de informação pelas mídias digitais e outros meios de comunicação de massa, modificou-se a forma de consumir e produzir a dança. No entanto, há poucos estudos, na área da Dança, sobre danças produzidas a partir da recepção e imitação de danças da mídia, com exceção apenas de alguns autores (TOMAZZONI, 2009; GUARATO, 2016). Além disso, seja freqüentando escolas, para dar aulas de dança, seja por relatos dos colegas de profissão, percebemos que existe ainda estranhamento, por parte da maioria dos docentes, quando os alunos, nas escolas, mencionam sobre o seu interesse pelos estilos de danças midiáticas.

A partir de apontamentos sobre questões epistemológicas que permeiam o debate pedagógico da área da Dança, buscaremos problematizar os preconceitos com relação a danças midiáticas e o pouco investimento em estudos sobre esse tema. Em seguida, apresentaremos o campo da cultura K-pop como o recorte analítico deste artigo, a partir de revisão bibliográfica internacional e nacional. E, por fim, discutiremos os resultados de um estudo sobre a dinâmica da expansão e do aprendizado não-formal da dança K-pop na cidade de Porto Alegre. Como base teórica em autores como Martín-Barbero, Stuart Hall, Michel Maffessoli e Judith Butler analisaremos o perfil dos grupos de Covers de dança K-pop na cidade, discutindo temas como cultura pop, juventude, identidade, neotribos e performances de gênero.

\section{As Danças Midiáticas e o campo da Dança:}

Atualmente, os cursos de graduação em licenciaturas em dança são uma área já consolidada no âmbito acadêmico, contando com um conjunto de diretrizes, regidos transculturalidade e performances de gênero. Revista da FUNDARTE. Montenegro, p.01-21, ano 21, no 45, junho de 2021.

Disponível em: http://.seer.fundarte.rs.gov.br/index.php/revistadafundarte/index> 30 de junho de 2021. 


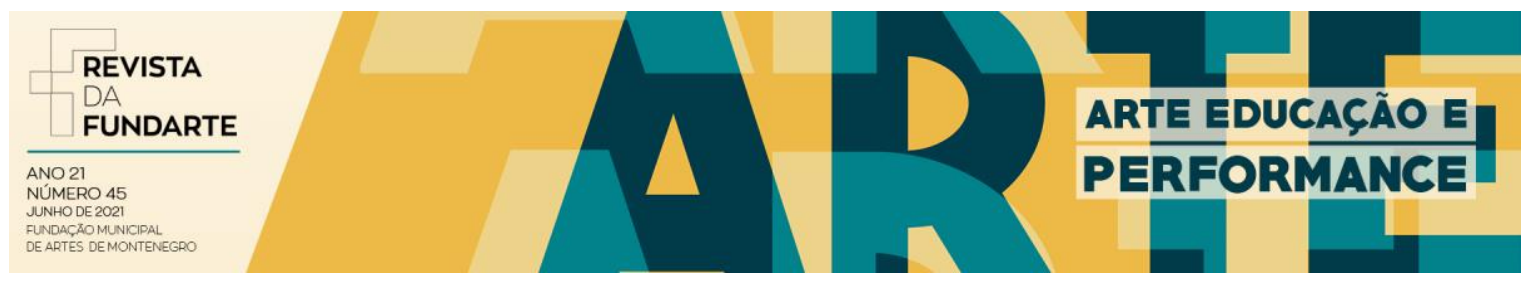

por dispositivos Constitucionais, Legais e normativos ${ }^{3}$. O seu campo teórico, no entanto, segue em permanente construção, debates e tensões entre suas várias perspectivas.

Algumas autoras que respaldam a trajetória de consolidação da área (KATZ, 2009; SOUZA, 2004; MARQUES, 2010) apresentam um discurso pedagógico desmerecedor da importância das danças midiáticas, como conteúdo a ser trabalhado em aulas de dança. Por exemplo, Souza $(2004$, p. 5) afirma que o vocabulário corporal dessas danças produzidas pela mídia é "restrito e pobre", com "ausência de liberdade de criação e expressão" porque o corpo é "submetido à reprodução de certos modelos". Marques (2010 p.33) considera as danças midiáticas (e muitas outras danças codificadas), como mera "cópia inconsciente" e "reprodução mecânica" e diz que seus dançarinos são "simples executores de tarefas, passivos e sem iniciativa" (p. 50).

Conforme Guaratto (2016), basicamente, aqueles/as que exercem esse preconceito com essas danças utilizam argumentos como o de que são danças dedicadas ao mercado e não à criação artística, ou de que são apenas cópia e reprodução, alijando processos de reflexão e autonomia crítica dos sujeitos que as praticam. O autor observa que parte do campo teórico pedagógico da dança no Brasil ignorou todas as discussões teóricas sobre as relações entre o mercado, a mídia e as culturas populares, em diversas áreas do conhecimento, que se seguiram à crítica ao conceito de indústria cultural (ADORNO e HORKHEIMER, 1983), no século $X X$. E considerou as danças midiáticas como danças que retiram a autonomia dos sujeitos, por serem pautadas em reprodução passiva.

$\mathrm{Na}$ perspectiva de Adorno e Horkheimer (1983), a industrialização e mercantilização dos bens culturais refletia, unicamente, os interesses do grupo

\footnotetext{
${ }^{3}$ Resolução CNE/CES №. 1 de 16 de janeiro de 2009; Resolução CNE/CES no 2, de 1ํ de julho de 2015 e Lei 13.278/2016, a qual inclui as artes visuais, a dança, a música e o teatro nos currículos da educação básica; e a nova lei que altera a Lei de Diretrizes e Bases da Educação Nacional (LDB Lei 9.394/1996) pautada nas Diretrizes Curriculares Nacionais (DCNs) do Curso de Graduação em Dança.
}

ANDREOLI, Giuliano Souza; FERNANDES, Braçi. O aprendizado informal da dança k-pop: juventude, transculturalidade e performances de gênero. Revista da FUNDARTE. Montenegro, p.01-21, ano 21, no 45, junho de 2021.

Disponível em: http://.seer.fundarte.rs.gov.br/index.php/revistadafundarte/index> 30 de junho de 2021. 


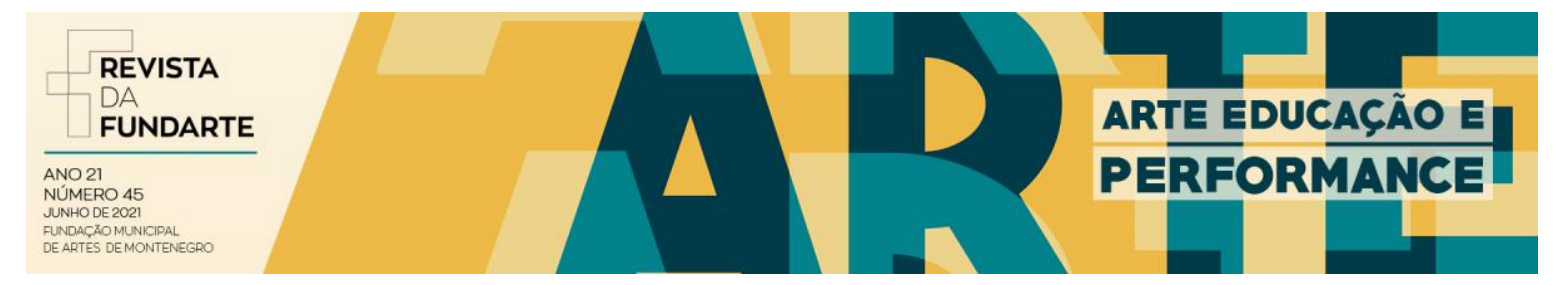

social específico detentor do capital. A indústria cultural era, portanto, uma forma de dominação totalizante do capitalismo, que imporia os seus símbolos sentidos e ideologias de forma unilateral o público consumidor sendo entendido como uma audiência passiva. Contra essa noção, muitos teóricos da segunda metade do século XX apresentaram um quadro mais complexo, onde a mídia não seria a única formadora dos modos de agir humanos. Sobre este debate teórico discorreremos aqui apenas brevemente, tal a quantidade de pesquisas que já o aplicam, já há mais de 30 anos, nos chamados estudos de recepção ${ }^{4}$.

Destacamos, aqui, o conceito de hibridismo cultural (HALL, 2013; CANCLINI, 2013), no qual compreende-se que os mercados e indústrias de massa intensificam as trocas culturais, levando a uma aceleração dos processos de mistura cultural, de forma que toda a cultura contemporânea é, em alguma medida, midiatizada. Essa condição da contemporaneidade torna mais evidente que: a) não existem fronteiras tão nítidas entre "cultura popular", "cultura erudita" e "cultura de massas"5; e b) as representações hegemônicas e contra-hegemônicas estão tanto na mídia quanto fora dela, sendo toda a cultura contemporânea um espaço para conflitos e negociações.

Destacamos, também, o conceito de mediação cultural (MARTíN-BARBERO, 2003; OROZCO, 2005) que se refere à interação entre o produtor de sentidos (a mídia, nesse caso) e os receptores (o público). Estudos nessa perspectiva evidenciam as dinâmicas de interação entre o mercado, a mídia e os sentidos construídos pelos próprios indivíduos na ressignificação dos símbolos e dos bens culturais massificados. E demonstram que as sensibilidades locais, inseridas em contextos sociais diversos, negociam com os valores hegemônicos, ocorrendo a

\footnotetext{
4 Sobre este assunto ler: WHITE, Robert. Recepção: a abordagem dos Estudos Culturais. Comunicação e Educação, São Paulo: n. 12, mai/ago, 1998. p.57-76.

${ }^{5}$ Burke (1989) evidencia que as culturas ditas eruditas e populares sempre foram influenciadas uma pela outra, ao longo da história. E chama de procedimento elitista 0 ato de acreditar que a denominada "popular" imita apenas grotescamente a cultura tida como " erudita".
}

ANDREOLI, Giuliano Souza; FERNANDES, Braçi. O aprendizado informal da dança k-pop: juventude, transculturalidade e performances de gênero. Revista da FUNDARTE. Montenegro, p.01-21, ano 21, no 45, junho de 2021.

Disponível em: http://.seer.fundarte.rs.gov.br/index.php/revistadafundarte/index> 30 de junho de 2021. 


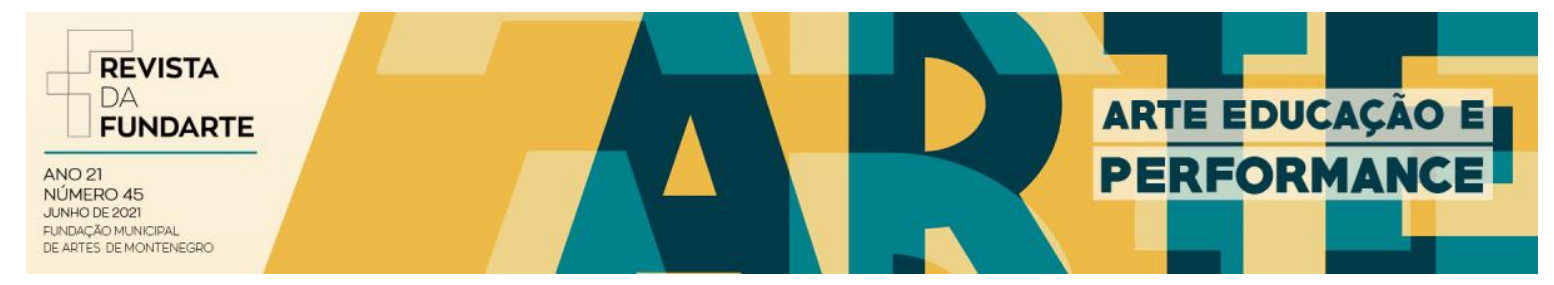

recepção dos bens simbólicos de distintas formas. Portanto, os receptores não são apenas agentes passivos. Assim:

\begin{abstract}
ao não negligenciarmos ou desqualificarmos as experiências em dança nos meios massivos, levamos em consideração que a vontade de dançar, de copiar e consumir o que é mostrado em mídias como televisão, filmes e vídeo clips não decorre exclusivamente de arranjos empresariais. Aliado aos apelos midiáticos e mercadológicos, tem de haver reconhecimento de valores compartilhados nos processos de interação social, pois são esses valores que criam cadeias significativas que possibilitam a existência e manutenção de danças no contexto midiático. (GUARATO, 2016, p.05-20).
\end{abstract}

No entanto, persiste, ainda hoje, um pensamento sobre dança que reproduz uma dicotomia entre mercado e arte (GUARATO, 2016) considerando que essas danças massificadas pela mídia excluem a liberdade de criação e a criatividade.

Conforme Tomazzoni (2009), o investimento da mídia na dança é bastante presente na cultura contemporânea. E, como ressalta Guarato (2016) essas danças presentes na Indústria Cultural midiática são, em sua maioria, provenientes da cultura popular urbana. Isso impõe ao campo teórico da dança a tarefa analítica de olhar para como as pessoas que dançam essas danças fazem uso desses bens culturais disponíveis na mídia, como as utilizam em seus meios sociais, entrelaçando as redes de significado dos seus fazeres quotidianos com as do mundo globalizado que os cerca. Para os objetivos deste artigo, escolhemos como recorte 0 campo da dança urbana midiática K-Pop.

\title{
Entendendo o campo de pesquisa: a Cultura K-Pop
}

K-pop é a contração de Korean Pop. É uma parte da "Hallyu", ou "Onda Coreana", termo que passou a designar, a partir de 2009, a difusão da indústria do entretenimento pop sul-coreano por todo o mundo (JIN, 2012). Até os anos 2000, as novelas televisivas eram o maior produto de exportação coreano (HUAT, 2010). Os grupos musicais de K-pop já existam desde 1990, no formato de 'girlbands' e

ANDREOLI, Giuliano Souza; FERNANDES, Braçi. O aprendizado informal da dança k-pop: juventude, transculturalidade e performances de gênero. Revista da FUNDARTE. Montenegro, p.01-21, ano 21, no 45, junho de 2021.

Disponível em: http://.seer.fundarte.rs.gov.br/index.php/revistadafundarte/index> 30 de junho de 2021. 


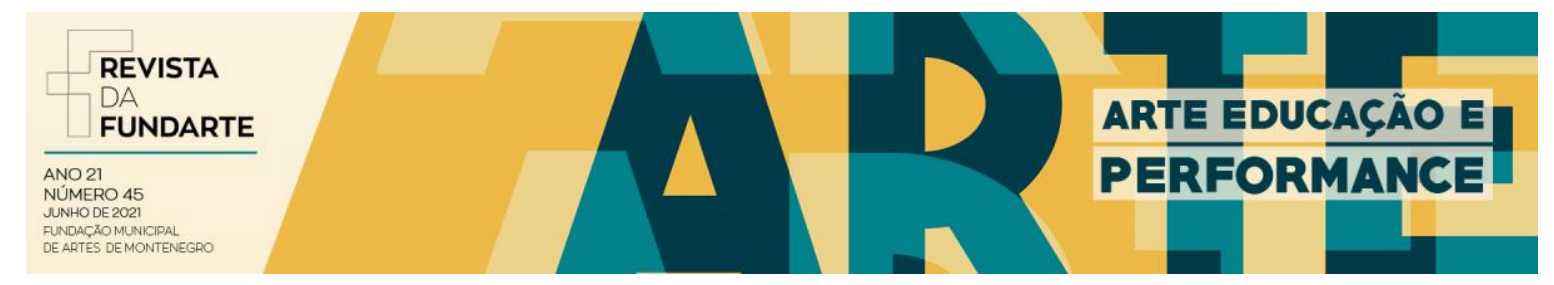

'boybands' 6 , derivado dos modelos da indústria pop norte-americana. E traziam um hibridismo inovador entre estilos musicais (Pop, Rock, Techno, Rap e Soul) e dança. Até que as novas mídias digitais (youtube, facebook, Twitter, etc.) facilitaram a sua difusão para além da Ásia e houve o crescimento de uma nova cena musical (SHIM, 2011).

No Brasil, começou a ter popularidade desde 2004 e se expandiu a partir de 2012, após a viralização, na internet, do clipe "Gangnam Style" do artista e compositor sul coreano PSY (CORDEIRO, 2013). Mesmo tendo uma língua desconhecida pelos fãs brasileiros, adquiriu significado para eles a partir de elementos já conhecidos pelo público ocidental: a matriz cultural midiática do Hip Hop e do Pop norte-americanos e a linguagem visual dos videoclipes (CRUZ, 2016). Muitos estudos (BERTO e ALMEIDA, 2015; CRUZ, 2016; SANTOS, 2016; LARANJEIRA, IRIART e LUEDY, 2018) têm apontado que a sua difusão no Brasil é um fenômeno que ocorre entre os jovens, demarcando fronteiras simbólicas de identidades juvenis.

O K-pop surgiu quando a Coréia estava sujeita a uma forte influencia da cultura norte-americana e a uma maciça neoliberalização econômica. E sua transnacionalização coincidiu com os agressivos esforços da Coréia para expandir a sua economia. Neste sentido, todos os estudiosos sobre o tema são unânimes em afirmar que o K-pop é parte da dominação da indústria cultural neoliberal na Ásia (CHUA e IWABUCHI, 2008; KIM, 2017). No entanto, como o K-pop se desenvolveu para além de suas fronteiras simbólicas originais, ele adquiriu também contornos transculturais.

Conforme Hall (2013) e Canclini (2013), na sociedade contemporânea, as subjetividades são construídas a partir de referencias globais que, muitas vezes, desprezam dimensões de espaço (pertencimentos regionais ou nacionais) e estabelecem jogos de identidades múltiplos. Para falar da forma como a cultura pop global estabelece, a partir de afinidades transculturais, o partilhamento de afetos e 0

\footnotetext{
${ }^{6}$ Bandas formadas por garotas ou garotos com habilidades musicais e de dança.
} transculturalidade e performances de gênero. Revista da FUNDARTE. Montenegro, p.01-21, ano 21, no 45, junho de 2021.

Disponível em: http://.seer.fundarte.rs.gov.br/index.php/revistadafundarte/index> 30 de junho de 2021. 


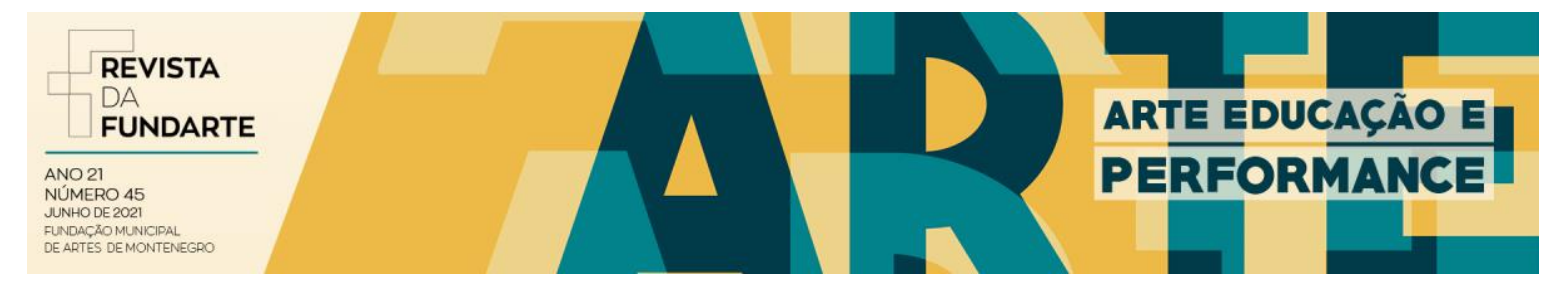

senso de identidade, alguns investigadores tem adotado conceitos como os de "estilos de vida", "cena" ou "neotribo" (BENNET \& KAHN-HARRIS, 2004). Para Mafessoli (1987), por exemplo, as "neotribos" vinculam os indivíduos a opções estilísticas e emocionais, sendo que o domínio estético é um importante fator para constituição de identidades. Martín-Barbero (2008) e Castells (2002) também observam que a estética é importante na construção das identidades juvenis contemporâneas mediadas por essas culturas.

De acordo com Berto \& Almeida (2015), Santos (2016), Laranjeira, Iriart \& LUEDY (2018), a maioria dos fãs de K-pop, no Brasil, são jovens, de origem não-asiática, que conheceram essa cultura na internet. Ou seja, o K-pop possui um forte caráter simbólico agregador de identidades juvenis e a Internet tem sido o espaço privilegiado da sua difusão. Incluem-se aí os espaços virtuais (youtube, instagram, etc) como ferramenta para compartilhar vídeos. Mas, além disso, esses estudos também têm apontado para a formação de circuitos culturais, que incluem shows, festivais competitivos e outros eventos de K-pop. O que tem estimulado jovens a se reunirem em grupos para ensaiar os Covers (a cópia das performances dos ídolos). Segundo Santos (2016), o Brasil tem cada vez mais eventos desse tipo, a maioria deles em São Paulo e no Rio.

É importante ressaltar que as coreografias de dança fazem parte do formato dos grupos artísticos de K-pop, que começaram a se popularizar no início do século XXI, como parte da Hallyu. E que a dança constituiu uma parte importante do seu sucesso atual entre os jovens (MARTINS e GRECCA, 2018).

\section{Quem dança o K-pop em Porto Alegre?}

Discutiremos, aqui, os resultados parciais de um estudo apoiado em pesquisa de campo de inspiração etnográfica, realizado em 2019, na cidade de Porto Alegre. Nesse estudo, buscou-se compreender como os produtos da Indústria Cultural da Hallyu afetam os processos de aprendizagem e de criação artística em dança. transculturalidade e performances de gênero. Revista da FUNDARTE. Montenegro, p.01-21, ano 21, no 45, junho de 2021.

Disponível em: http://.seer.fundarte.rs.gov.br/index.php/revistadafundarte/index> 30 de junho de 2021. 


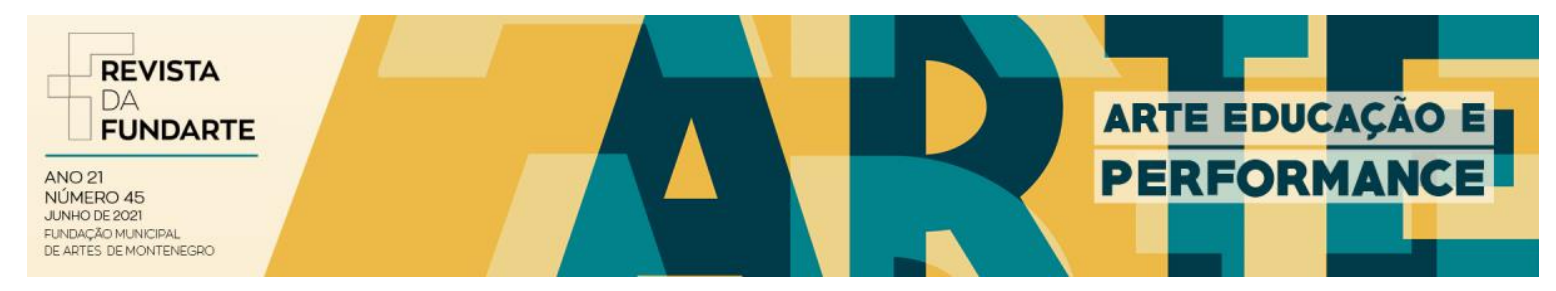

Tivemos por intenção compreender o perfil dos praticantes de dança K-pop, as formas que utilizam para aprender essa dança e quais significados a sua prática agrega. Os dispositivos metodológicos construídos foram observações participantes, acompanhando os ensaios e eventos de grupos e coletivos culturais orientados para a prática do Cover.

Sabíamos, previamente, que, por essa dança popular ser massificada e constituir o que muitos consideram como um "modismo", isto é, estar em alta nas mídias sociais, o seu aprendizado ocorreria predominantemente por meios informais. Além disso, a nossa entrada no campo foi facilitada porque um dos pesquisadores já possuía pertencimento a um grupo de Cover de K-pop e, através de sua rede de relações, ajudou a localizar outros grupos que também se reuniam para ensaiar suas performances artísticas.

As observações foram realizadas em dois locais distintos. A primeira foi em um evento voltado apenas para o K-Pop, chamado K-Union, que ocorre duas vezes por ano na cidade. $O$ segundo foi nos fins de semana, nos diversos andares do espaço público Casa de Cultura Mario Quintana, onde praticantes se reuniam para ensaiar. Foram realizadas também entrevistas semi-estruturadas, com perguntas a respeito do início da prática, o motivo pelo qual escolhiam o local onde ensaiam, a diversidade de integrantes existentes no meio e a vontade ou não de se profissionalizarem na dança.

Todos os sujeitos de pesquisa afirmaram utilizar o local por não terem condições financeiras para locarem uma sala para ensaios, o que seria o ideal. O que reforça vidências de pesquisas anteriores, de que o K-pop, no Brasil, tem agregado sentido junto a um público periférico, localizado à margem da cultura hegemônica de dança, em contextos sem acesso à arte (LARANJEIRA, IRIART e LUEDY, 2018).

Percebemos que os ensaios atraem outros jovens que vão lá apenas para se reunir, conversar e dançar junto, mesmo não sendo praticantes de K-pop. Nas palavras de um dos sujeitos da pesquisa: "muitos grupos e até mesmo amizades começaram neste local". O que evidencia que a arte K-pop é elemento central de transculturalidade e performances de gênero. Revista da FUNDARTE. Montenegro, p.01-21, ano 21, no 45, junho de 2021.

Disponível em: http://.seer.fundarte.rs.gov.br/index.php/revistadafundarte/index> 30 de junho de 2021. 


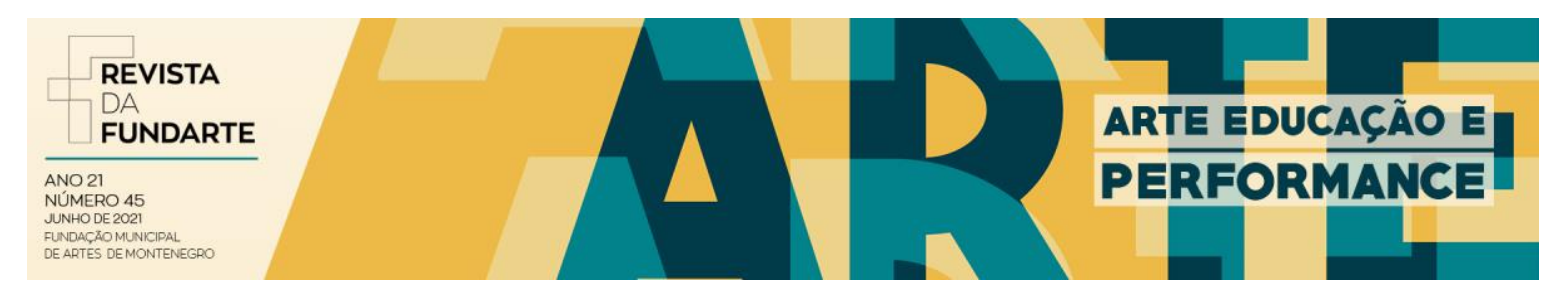

produção de sentidos que demarcam certas fronteiras simbólicas de pertencimento, transformando os ensaios dos grupos também em um ponto de encontro social.

Conforme Santana (2018), as referências simbólicas do K-pop constituem universos de códigos partilhados, que permitem articular valores identitários, a partir dos quais os jovens podem detectar a "tribo" que mais Ihes representa, para realizarem o anseio de sentir-se pertencendo a algum grupo social. E potencializam a formação daquilo que Magnani (2005) chama de circuitos culturais juvenis, que são redes de convivência que produzem novas sociabilidades formadoras de subculturas juvenis.

Com relação aos interesses dos praticantes, poucos declararam ter como objetivo se profissionalizarem em dança ou mesmo se tornarem grandes dançarinos dentro do meio do K-pop. A grande maioria afirmou praticar apenas "por diversão". Entre os sujeitos da pesquisa, a maioria afirmou não estudar dança em universidades ou ter treinamento em dança em escolas comerciais. Essa falta de interesse pela profissionalização necessita de maiores aprofundamentos, uma vez pouco se tem pesquisado, no Brasil, sobre o que jovens dançarinos inseridos fora dos contextos de aprendizagem formal em dança pensam sobre a educação em dança nas universidades.

\section{O aprendizado da dança pela cópia: para além da reprodução passiva}

Muitas danças midiáticas têm gerado processos de aprendizado fora da educação formal, sem a presença de um professor ou de um instrutor de dança (TOMAZZONI, 2009). O que caracteriza o que a teoria educacional tem chamado de educação nãoformal (LIBÂNEO, 2010, GADOTTI, 2005) ou então como processos informais de aprendizagem (GREEN, 2000; MARCELINO e BEINEKE, 2014).

\footnotetext{
7 A categorização mais conhecida é a divisão da educação em três diferentes tipos - formal, não formal e informal - tal como proposta por Philip H. Coombs, Roy C. Prosser e Manzoor Ahmed (1973). Mas há variações de classificação, dependendo dos autores utilizados.

ANDREOLI, Giuliano Souza; FERNANDES, Braçi. O aprendizado informal da dança k-pop: juventude, transculturalidade e performances de gênero. Revista da FUNDARTE. Montenegro, p.01-21, ano 21, no 45, junho de 2021.

Disponível em: http://.seer.fundarte.rs.gov.br/index.php/revistadafundarte/index> 30 de junho de 2021.
} 


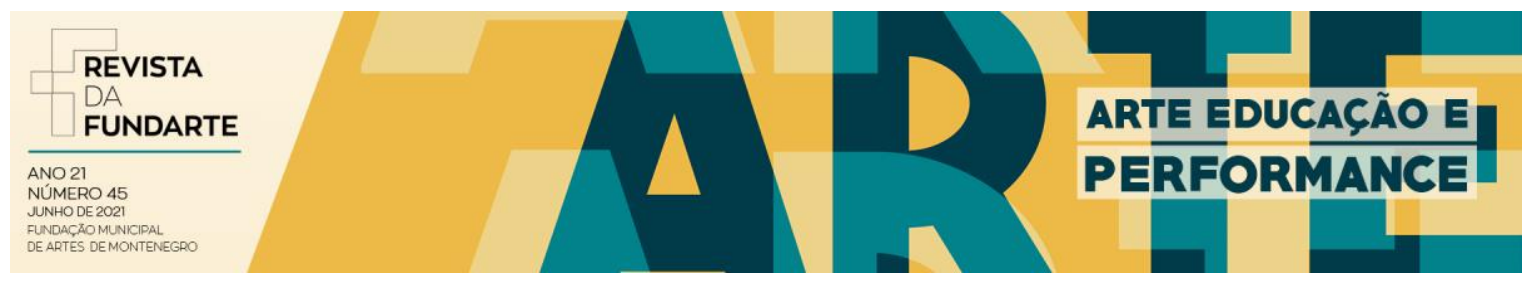

No contexto da cidade de Porto Alegre, observamos que aulas pagas de K-pop, em Workshops ou em academias de dança, emergem apenas recentemente, como um novo mercado. Mas ainda são bem escassas e de pouco acesso para os jovens de classe popular. Por isso, já está naturalizado nesse meio que o aprendizado se dê em casa, por conta própria, ou junto a outros fãs, sem um instrutor ou um professor. Dos praticantes entrevistados nessa pesquisa, todos relataram que começaram a praticar através das redes sociais (youtube, facebook e instagram), copiando e repetindo coreografias.

$\mathrm{Na}$ perspectiva teórica fundamentada nesse artigo, a imitação dessas performances veiculadas pela Internet não deve ser vista apenas como um assujeitamento dos jovens às Indústrias Culturais Globais. E entendemos que conceitos como o de Hibridismo ou de Mediação Cultural descrevem mais adequadamente esse fenômeno.

Conforme a teórica da dança Susana Klein (2018), copiar uma coreografia é sempre um processo de tradução cultural. A autora refere-se a uma "prática de negociação", na qual, mesmo a Indústria Cultural imponha um modelo de música e de dança, há sempre alterações nos significados em cada contexto social:

No processo da transmissão, altera-se também o valor dos bens imateriais, como o saber coreográfico ou da dança. Isso sobretudo porque cada um atribui uma importância diferente ao que é recebido e, assim, assume a responsabilidade de maneira distinta. Mas também porque o bem imaterial é colocado, a cada transmissão, em um novo contexto pessoal, vivencial, histórico e cultural, engendrando, através de novos enquadramentos, sempre novos sentidos, novos significados, novos valores. (KLEIN, 2018, p.397).

De fato, fora do campo da dança, estudos etnográficos (JUNG, 2011; GUEVARA, 2014; KANG, 2014; CORTEZ e ALBUQUERQUE, 2015; NECULA, 2017) tem observado que, através de diferentes processos culturais de apropriação, ressignificação e tradução, os fãs de K-pop constroem novos sentidos sobre as suas práticas, a partir dos produtos transnacionais consumidos. E que a identificação com

ANDREOLI, Giuliano Souza; FERNANDES, Braçi. O aprendizado informal da dança k-pop: juventude, transculturalidade e performances de gênero. Revista da FUNDARTE. Montenegro, p.01-21, ano 21, no 45, junho de 2021.

Disponível em: http://.seer.fundarte.rs.gov.br/index.php/revistadafundarte/index> 30 de junho de 2021. 


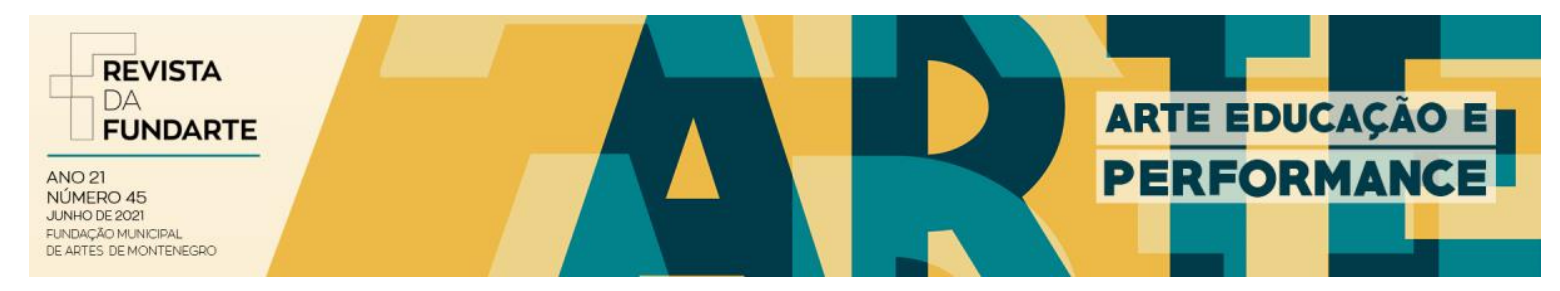

essa cultura midiática se dá nessa articulação entre os elementos locais e globais, produzindo novos sentidos. Segundo Yonn (2017), sem esses processos de tradução cultural, o K-pop não seria recebido com entusiasmo por esses fãs e não integraria o seu cotidiano.

Para Jung (2011), Guevara (2014) e Kang (2015), na Ásia, ao incorporar novos "estilos de vida" a partir da Indústria Cultural da Hallyu, os jovens criam novas identidades inexistentes nas suas localidades. KO et all (2014), em pesquisa realizada no Brasil e no Peru, chegam às mesmas conclusões. E evidenciam que o K-pop oferece uma oportunidade de "escapar" das identificações vinculadas ao baixo perfil econômico e a pertencimentos étnico-raciais em localidades da periferia.

Em nossa pesquisa, as dinâmicas de apropriação e tradução cultural observadas incluíram: a) a imersão na cultura musical do K-Pop e o aprendizado musical de ouvido; b) a aprendizagem da dança por meio da observação e imitação; c) a prática em grupo, que é sistemática e pode ser estruturada em diversos modelos (ensaios, encontros, eventos, etc.). Constatamos que todos esses processos informais de aprendizagem, através dos quais os indivíduos educam a si mesmos e aos outros, possuem dimensões criativas. Por exemplo, ao observarem e copiarem as coreografias dos vídeos dos ídolos, a minuciosa busca por perfectibilidade levou os sujeitos da pesquisa a desenvolverem novas habilidades práticas específicas, fazendo surgirem novas técnicas corporais.

$\mathrm{Na}$ etnografia de Santos (2016), em São Paulo, o autor observou que, mais do que imitar mecanicamente, os fãs procuravam atingir um modo específico de performar os Covers, que implicava em "harmonizar-se" ao modelo original, em "tentar passar o que o ídolo passa". E, dessa forma, os corpos criavam um comportamento performático novo, que estava situado entre o original, observado nos vídeos, e a cópia.

Igualmente, nesta pesquisa, percebemos que as reproduções ou cópias não eram idênticas aos originais. Pelo contrário, notamos modificações no léxico corporal e a exploração de uma maior variabilidade de qualidades de movimento e de gestos transculturalidade e performances de gênero. Revista da FUNDARTE. Montenegro, p.01-21, ano 21, no 45, junho de 2021.

Disponível em: http://.seer.fundarte.rs.gov.br/index.php/revistadafundarte/index> 30 de junho de 2021. 


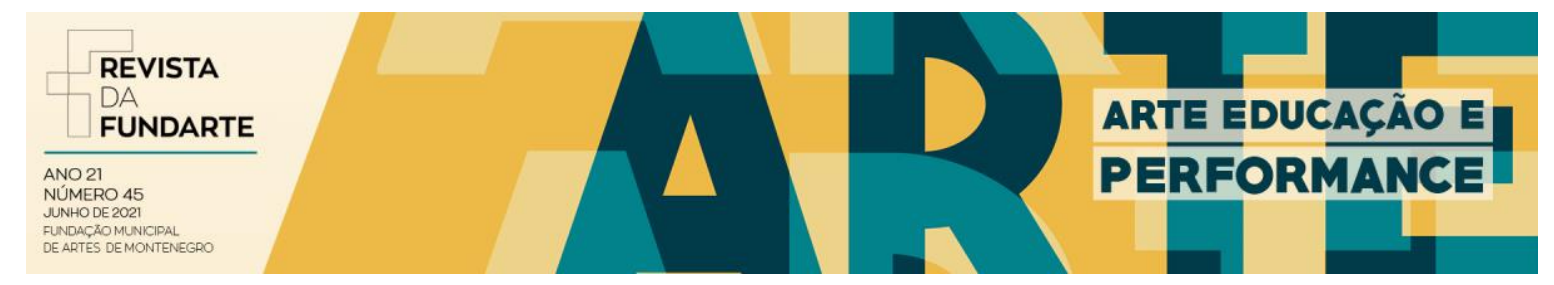

entre os praticantes do que entre os ídolos dos vídeos nos quais eles se inspiravam. Mesmo que, na perspectiva dos praticantes, dançar K-Pop é "se tornar o ídolo", o aprendizado dessa dança por meio da observação e imitação não demonstrou uma atitude passiva e nem fala de capacidade criativa. Pelo contrário, foi elemento estruturante do processe de educação dos seus corpos na aquisição de novas habilidades em dança.

A pesquisa também evidenciou o papel articulador e mobilizador de suas ações, ao produzirem arte fora do circuito oficial da dança artística de Porto Alegre, estava, em grande medida, associado a questões de pertencimento social envolvendo a construção cultural das suas identidades de gênero. Abordaremos isso na próxima sessão.

\section{O Cover de K-Pop como performance de gênero}

A partir dos contextos observados nessa pesquisa, constatamos que, para os jovens praticantes de K-pop, performar os Covers implica em mais do que simplesmente se vestir como e imitar as coreografias dos seus ídolos. As roupas, os adereços, as cores com as quais pintam seus cabelos e os modos próprios de expressão corporal que fazem parte dos pertencimentos tribais dessa cultura juvenil, tanto marcam a estética artística quanto o pertencimento ao grupo social, agregando os sentidos de estar junto e os valores de comunhão, que segundo Mafessoli (1987) são característicos dos fenômenos tribalizantes. O corpo serve como um outdoor afetivo, por meio de signos e símbolos, que convidam o contato de outros membros da mesma "tribo".

Essas estéticas levam os indivíduos a compartilharem experiências, sentimentos comuns, reafirmando no palco formas de agir, de se vestir, e de se expressar que seriam malvistas em outras ocasiões, em determinados contextos sociais. Assim, eles também representam a realidade de quem eles são na vida quotidiana, no interior do seu grupo social. É desse modo, por meio da performance, como um transculturalidade e performances de gênero. Revista da FUNDARTE. Montenegro, p.01-21, ano 21, no 45, junho de 2021.

Disponível em: http://.seer.fundarte.rs.gov.br/index.php/revistadafundarte/index> 30 de junho de 2021. 


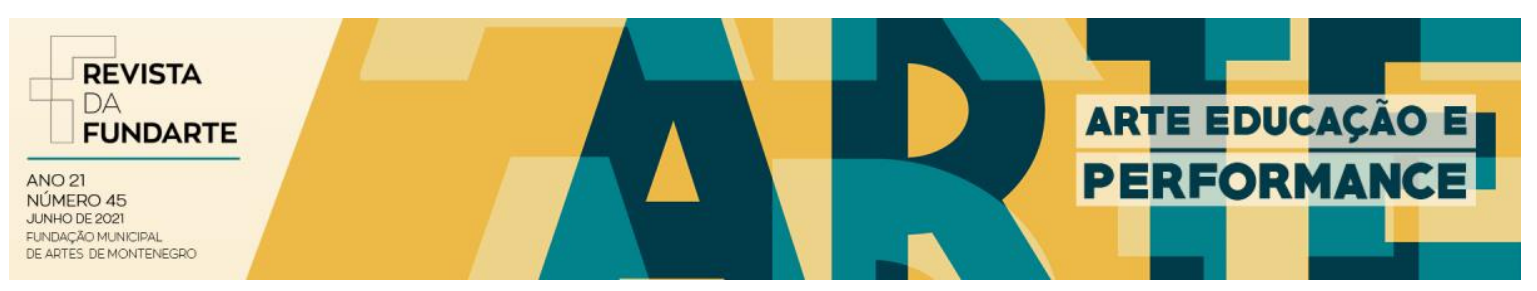

comportamento restaurado (SCHECHNER, 2011; LIGIÉRO, 2012), que os k-popers acionam para si próprio algo das performances, construindo suas identidades enquanto imitam os seus ídolos.

Assim, nessa pesquisa, constatamos que o simbolismo do K-pop funciona tanto como marcador de pertença quanto de diferença, potencializando processos de sociabilidade associados à identificação e à diferenciação, demarcando, para além do gosto musical, fronteiras simbólicas, entre as quais, as de juventude e também de gênero.

Em estudos anteriores sobre o perfil dos K-popers no Brasil (CORDEIRO, 2013; BERTO e ALMEIDA, 2015; SANTANA \& SANTOS, 2019), já havia sido apontada uma presença predominante de meninas. Nessa pesquisa, percebemos o mesmo perfil. Porém, também notamos a presença de meninos transgêneros. $E$ foi constatado que eles são muito bem aceitos no grupo, por a grande maioria já fazer parte da cultura LGBTQI+. Assim, a pesquisa sugere que o perfil dos jovens pode estar mudando no Brasil, aproximando-se do perfil já observado em estudos internacionais (KANG, 2014; GUEVARA, 2014) ${ }^{8}$. Porém, considerando que o universo completo dos fãs de K-pop, no Brasil, ainda não é conhecido, essa questão demanda ainda maiores pesquisas.

Com relação essa temática, é importante ressaltar que a lógica dominante da nossa sociedade é regida pela pressuposição de que apenas a orientação heterossexual é normal, a heteronormatividade (BUTLER, 2017), que dá origem à homofobia. Para reforçar-se, essa norma mantém no gênero um controle simbólico. É o chamado binarismo de gênero: a classificação que divide em duas categorias de identidade o "sexo" e o "gênero", colocando como possível apenas o homem/masculino e a mulher/feminino (CARDIN e CAVALHEIRO, 2019, p.91). Quando não há identificação entre essas normas e a identidade subjetiva (psique)

\footnotetext{
${ }^{8}$ Kang (2014), por exemplo, demonstrou que os grupos de covers de K-pop, na Tailândia permitem a homens gays expressarem uma performance de feminilidade transgressora. Também para Guevara (2014) esses grupos, nas Filipinas, revelaram-se um espaço potente para a elaboração de identidades gays.
} transculturalidade e performances de gênero. Revista da FUNDARTE. Montenegro, p.01-21, ano 21, no 45, junho de 2021.

Disponível em: http://.seer.fundarte.rs.gov.br/index.php/revistadafundarte/index> 30 de junho de 2021. 


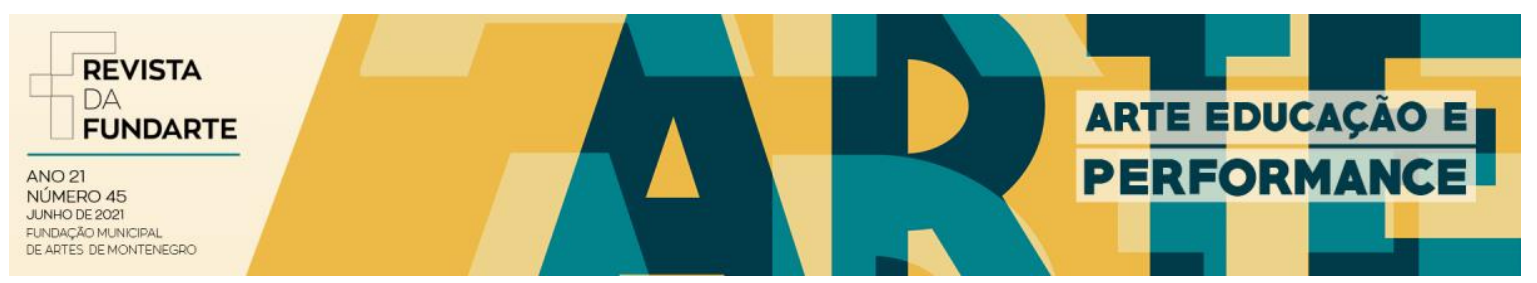

da pessoa, temos a transgeneridade (JESUS, 2012). Os transgêneros "se sentem e desejam viver e ser reconhecidos como uma pessoa de outro gênero e não o esperado pela sociedade com base no sexo biológico de seu nascimento" (COELHO, \& SAMPAIO, 2014, p.13).

A pesquisa demonstra que a identificação com os elementos estéticos da cultura K-pop, que adquirem significado predominantemente para mulheres e sujeitos transgêneros, é um fator importante para o pertencimento a essa cultura juvenil. A partir dos imaginários acionados pela Indústria Cultural, ocorre a incorporação de modelos alternativos de feminilidade e masculinidade, oriundos da cultura coreana, com estéticas que fogem às normas de gênero predominantes em nossa sociedade.

Conforme Louro:

A inscrição dos gêneros - feminino ou masculino - nos corpos é feita, sempre, no contexto de uma determinada cultura e, portanto, com as marcas dessa cultura. As possibilidades da sexualidade - das formas de expressar os desejos e prazeres - também são sempre socialmente estabelecidas e codificadas. (LOURO, 2013, p.11).

Uma vez que a cultura pop massificada não é apenas consumida, pois no ato mesmo de consumir bens culturais, está-se criando e produzindo algo novo (CLARKE et al., 2006), a prática do Cover de K-pop atrai muitas meninas e indivíduos transgêneros ou de outras categorias LGBTQls porque a aparência, as vestimentas e os modos de ser dos ídolos K-Pop invocam imaginários e potencializam a construção de novas performances artísticas de gênero. Estas, por sua vez, também estetizam a vida social, ao ponto do mesmo tipo de roupa, cabelos coloridos e outros elementos serem os identificadores de uma sub-cutura juvenil, ou seja, serem utilizados na sua vida quotidiana. Assim, a característica dos grupos que vivenciam a cultura K-pop como "tribos" juvenis torna difícil identificar até onde vai e a construção social do gênero, enquanto identidade, e onde começa o cosplay, a performance artística coreana carregada de códigos e elementos simbólicos de gênero.

ANDREOLI, Giuliano Souza; FERNANDES, Braçi. O aprendizado informal da dança k-pop: juventude, transculturalidade e performances de gênero. Revista da FUNDARTE. Montenegro, p.01-21, ano 21, no 45, junho de 2021.

Disponível em: http://.seer.fundarte.rs.gov.br/index.php/revistadafundarte/index> 30 de junho de 2021. 


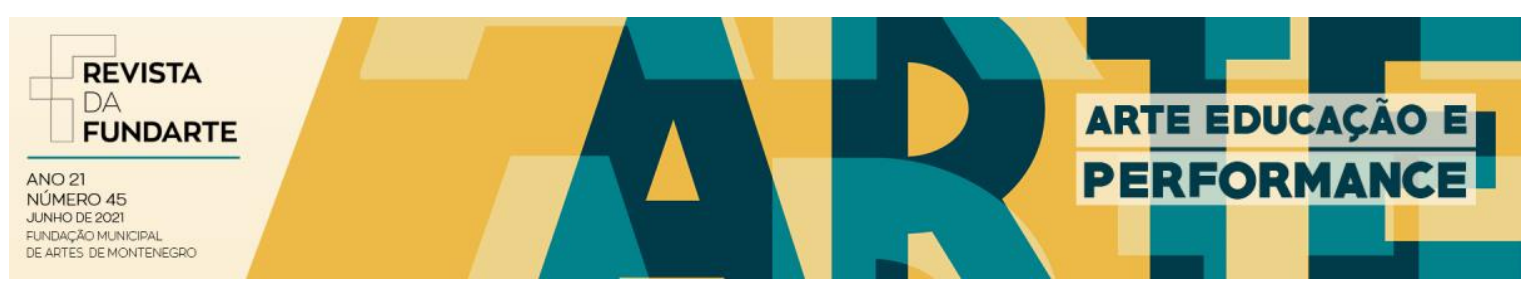

A pesquisa evidenciou que, a partir e através dos bens culturais midiatizados, a cultura global K-pop pode gerar experiências singulares, através da recepção e da sua ressignificação, produzindo novos sentidos. A dinâmica interativa na negociação dos símbolos culturais, reconfigurando as identidades de gênero desses sujeitos brasileiros, a partir de modelos de masculinidade e feminilidade coreanos, evidencia a relação entre local e global, o periférico e o hegemônico, o consumo e a produção, tão característica dos fenômenos de hibridismo cultural, tal como discutido por Canclini (2013), que nos leva a pensar de forma complexa as relações entre cultura e poder.

\section{CONSIDERAÇÕES FINAIS}

Com esse artigo, pretendemos trazer uma reflexão teórica sobre a importância do tema das danças midiáticas, para a sua inclusão como conteúdo e como tema para pesquisas nas universidades de dança. Apesar de haverem muitos estudos sobre Kpop além da Ásia, relativamente poucas pesquisas examinam as recriações feitas, no Brasil, daqueles bens culturais que a Indústria Cultural global coreana veicula, com atenção à reorganização dos símbolos cultuais e à heterogeneidade das apropriações dessa cultura. Esse desconhecimento de um fenômeno social que vem abrangendo uma geração é, muitas vezes, acompanhado de preconceitos. Assim, é importante que professores/as de dança compreendam o interesse dos jovens e sua inserção nessas práticas, uma vez que tais jovens estão nas escolas.

Concluímos que o K-Pop, dentre muitas outras culturas midiáticas veiculadas na sociedade global atual, é elemento central para a produção de sentidos que demarcam fronteiras simbólicas identitárias entre jovens que pertencem a certas "tribos" sociais. E que a globalização está diretamente relacionada ao surgimento de novos dançarinxs e de grupos de dança. Como esses jovens, em sua grande maioria, não estão ligados a nenhuma instituição como as Universidades de dança, isso os tem levado a construírem processos de aprendizagem informal. A pesquisa transculturalidade e performances de gênero. Revista da FUNDARTE. Montenegro, p.01-21, ano 21, no 45, junho de 2021.

Disponível em: http://.seer.fundarte.rs.gov.br/index.php/revistadafundarte/index> 30 de junho de 2021. 


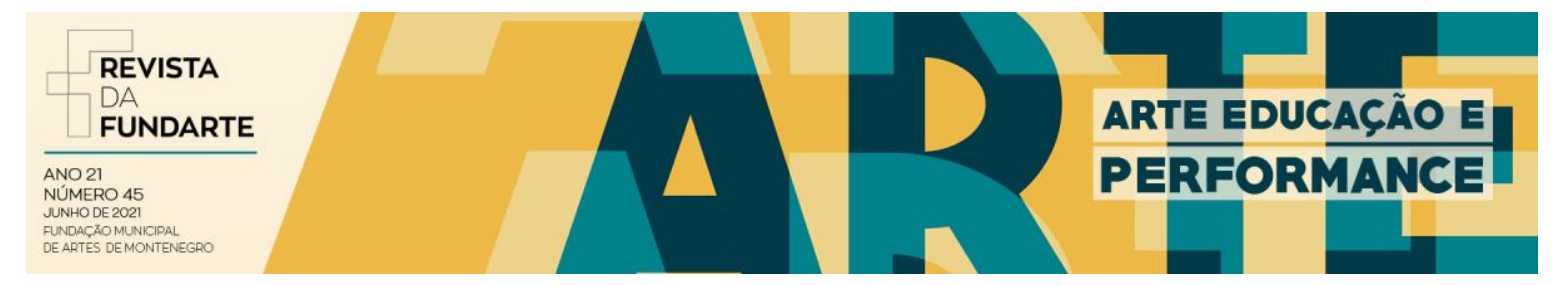

aponta, portanto, para a necessidade de mais estudos sobre esses espaços e contextos de aprendizado de dança.

Concluímos que os produtos da indústria K-pop potencializam processos informais de aprendizagem e a sociabilidade entre jovens em suas diferenças de gênero, à margem da cultura hegemônica de dança. A pesquisa constata que há uma articulação entre os elementos estéticos do K-Pop e modelos de feminilidade ou de masculinidade alternativos, que se contrapõe aos modelos de masculinidade hegemônicos. Por esse motivo, o K-Pop parece constituir, pelo menos no contexto da cidade observada, uma cultura juvenil marcadamente LGBTQI, atraindo muitos meninos transgêneros. E a prática da recriação das performances artísticas repercute na vida quotidiana e na construção da identidade de gênero dos indivíduos.

\section{Referencias:}

ADORNO, Theodor W.; HORKHEIMER, Max. A indústria cultural: o esclarecimento como mistificação das massas. In: ADORNO, T. Dialética do esclarecimento. Rio de Janeiro: Zahar, 1983, p. 99-138.

BENNET, Andy; \& KAHN-HARRIS, Keith. After Subculture. Critical Studies in Contemporary Youth Culture, Hampshire, Palgrave Macmillan, 2004. pp. 1-18.

BERTO, Rachel G.; e ALMEIDA, Mariza C. Quem são os fãs de K-pop no Brasil? Revista Tecnologia e Cultura. Rio de Janeiro, n.25, ano 17, jan/jun, 2015. p.3-44.

BURKE, Peter. Cultura popular na Idade Moderna. São Paulo: Companhia das Letras, 1989.

BUTLER, Judith. Problemas de gênero: feminismo e subversão da identidade. Tradução de Renato Aguiar. Rio de Janeiro: Civilização Brasileira, 2017.15ed.

CANCLINI, Nestor G. Culturas Híbridas: estratégias para entrar e sair da modernidade. São Paulo: Editora da Universidade de São Paulo, 2013.

CARDIN, Valéria S. G.; CAVALHEIRO, Nathan P., Do direito fundamental à uma educação para além dos padrões binários de gênero. In: BAHIA, Alexandre G. M. F.; transculturalidade e performances de gênero. Revista da FUNDARTE. Montenegro, p.01-21, ano 21, no 45, junho de 2021.

Disponível em: http://.seer.fundarte.rs.gov.br/index.php/revistadafundarte/index> 30 de junho de 2021. 


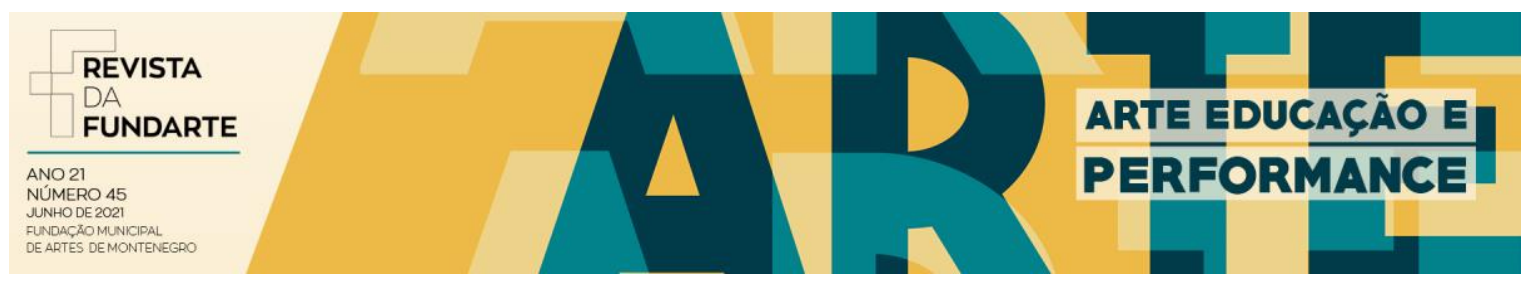

COSTA, Fabrício V.; GOMES, Magno F. (orgs.) - Gênero, sexualidade e direitos fundamentais para além do binarismo - Porto Alegre, RS: Editora Fi, 2019.

CASTELLS, M. O poder da identidade. $3^{\circ}$ ed. v. 2. Rio de Janeiro: Editora Paz e Terra, 2002.

CLARKE, John, et al. Subcultures, cultures and class, In: HALL, S. e JEFFERSON, T. (orgs.), Resistance through Rituals: Youth Subcultures in Post-War Britain. Londres e Nova lorque, Routledge, 2006, p.3-59.

CHUA, B.H., and IWABUCHI, K. (eds.) Introduction: East Asian TV Dramas: Identifications, Sentiments and Effects. In: East Asian Pop Culture: Analysing the Korean Wave, Aberdeen: Hong Kong University Press, 2008. p.1-12.

COELHO, Maria T. A. D.; SAMPAIO, Liliana L. P. As transexualidade na atualidade: aspectos conceituais e contexto. In: COELHO, Maria T. A. D.; SAMPAIO, Liliana L. P. (Org.). Transexualidades: um olhar multidisciplinar. Salvador: EDUFBA, 2014.

COOMBS, Philip H.; PROSSER, Roy; MANZOOR, Ahmed. New paths to learning for rural children and youth. New York: International Council for Education Development, 1973. $133 \mathrm{p}$.

CORDEIRO, Talita G. O fenômeno k-pop no Brasil: práticas de lazer a partir da web 2.0. Monografia (Bacharelado em Lazer e Turismo). Escola de Artes Ciências e humanidades da Escola de São Paulo. São Paulo, 2013.

CORTEZ, Crystal; ALBUQUERQUE, Alfonso. Cultura pop e política na nova ordem global: lições do Extremo Oriente. In: SÁ, Simone Pereira; CARREIRO, Rodrigo; FERRARAZ, Rogerio (Org.) Cultura Pop. Salvador/Brasília: Edufba/Compós, 2015. $296 \mathrm{p}$.

CRUZ, Caio A. E precisa falar coreano? Uma análise cultural do K-Pop no Brasil. 104 f. il. 2016. Monografia - Faculdade de Comunicação, Universidade Federal da Bahia, Salvador, 2016.

GADOTTI, Moacir. A questão da educação formal/não-formal. Droit à l'education: solution à tous les problèmes sans solution? Institut International des droits de l'enfant, Sion, 2005.

GREEN, Lucy. Poderão os professores aprender com os músicos populares? Revista Música, Psicologia e Educação, Porto, n. 2, p. 65-80, 2000.

GUARATO, Rafael. Dança e os meios de comunicação de massa. Urdimento, v.2, n.27, Dezembro, 2016. p. 05-20.

ANDREOLI, Giuliano Souza; FERNANDES, Braçi. O aprendizado informal da dança k-pop: juventude, transculturalidade e performances de gênero. Revista da FUNDARTE. Montenegro, p.01-21, ano 21, no 45, junho de 2021.

Disponível em: http://.seer.fundarte.rs.gov.br/index.php/revistadafundarte/index> 30 de junho de 2021. 


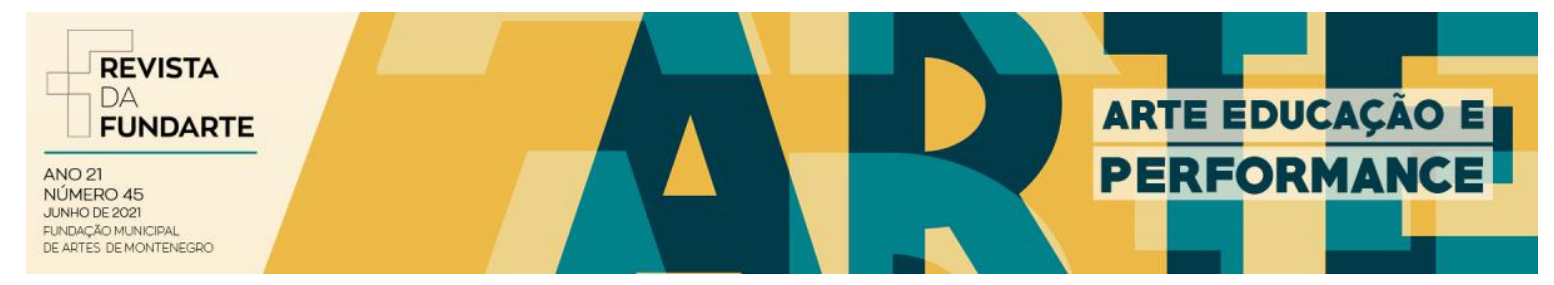

GUEVARRA, Alona U. Creating a Safe Space for Queer Teens?: Some Initial Findings on Queer Teens in K-pop Cover Groups and Fan Community. The AlKS Corean Studies Conference Proceedings, vol.1, 2014.

HALL, Stuart. A identidade cultural na pós-modernidade. Tradução: Tomaz Tadeu da Silva, Guacira Lopes Louro, 11ํe. ed. Rio de Janeiro: DP\&A, 2011.

HUAT, Chua Beng. Korean Pop Culture. Malaysian Journal Of Media Studies, Malasia, v. 12, n. 1, p.15-24, 2010.

JESUS, Jaqueline Gomes de. Orientações sobre identidade de gênero: conceitos e termos. 2. ed. Brasília, 2012.

JIN, Dal Young. Hallyu 2.0: The New Korean Wave in the Creative Industry. International Institute Journal, v. 2, n. 01, 2012.

JUNG, Sun. "K-pop, Indonesian Fandom, and Social Media." In: REID, Robin Anne \& GATSON, Sarah (org.) Race and Ethnicity in Fandom, Transformative Works and Cultures, no. 8, 2011.

KANG, Dredge Byung'chu. Idols of Development: Transnational Transgender Performance in Thai K-Pop Cover Dance. Transgender Studies, vol.1, n.4, 2014. p.559-571.

KATZ, Helena. A diferença entre arte e cultura. Jornal Urbano, São Paulo, 22 abr. 2009, p. 3.

KIM, Yoon-mi. Between Hybridity and Hegemony in K-Pop's Global Popularity: A Case of Girls' Generation's American Debut. International Journal of Communication. n.11, 2017.

KLEIN, Susane. Transmitir a Dança: legado e tradução das coreografias de Pina Bausch Rev. Bras. Estudo da Presença, Porto Alegre, v. 8, n. 3, p. 393-420, jul./set. 2018.

KO, N. C.; No, S., Kim; J.-N.., \& Simoes R. G. Landing of the wave: Hallyu in Peru and Brazil". Development and Society, vol.43, n.2, 2014. p.297-350.

LARANJEIRA Denise H.P.; IRIART, Mirella Figueiredo; LUEDY Eduardo. Arte como política de resistência: dispositivos cartográficos na apreensão de práticas culturais juvenis em uma cidade do Nordeste do Brasil. Etnográfica. Revista do Centro em Rede de Investigação em Antropologia, vol. 22, n.2, 2018. p. 427-452.

ANDREOLI, Giuliano Souza; FERNANDES, Braçi. O aprendizado informal da dança k-pop: juventude, transculturalidade e performances de gênero. Revista da FUNDARTE. Montenegro, p.01-21, ano 21, no 45, junho de 2021.

Disponível em: http://.seer.fundarte.rs.gov.br/index.php/revistadafundarte/index> 30 de junho de 2021. 


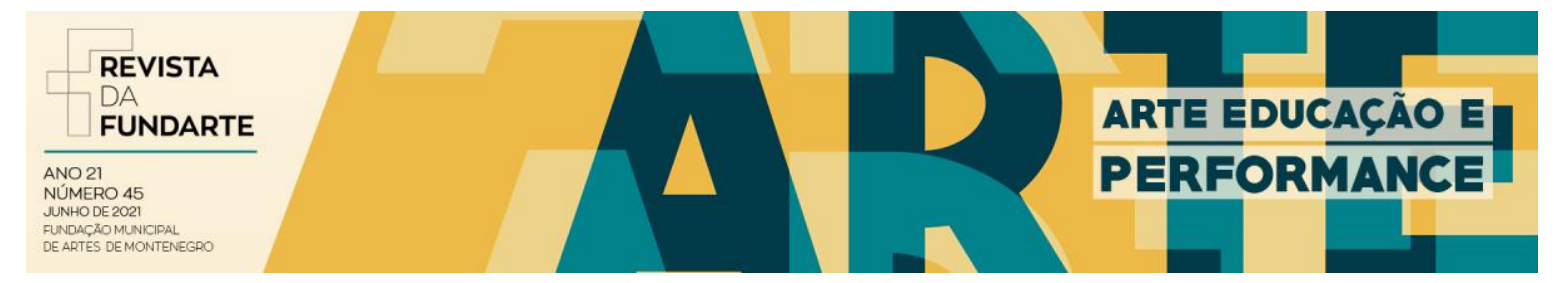

LIBÂNEO, José Carlos. Pedagogia e pedagogos para quê? 12 ed. São Paulo, Cortez, 2010, $208 \mathrm{p}$.

LIGIÉRO, Zeca. Performance e Antropologia de Richard Schechner. Tradução: Augusto Rodrigues da Silva Junior. Rio de janeiro: Mauad X, 2012.

LOURO, Guacira Lopes. Pedagogias da sexualidade. In: LOURO, Guacira Lopes (org.). O corpo educado. Pedagogias da sexualidade. $3^{\circ}$ ed. Belo Horizonte: Autêntica Editora, 2013.

LOVE, B. Encyclopedia of unusual sex practices. Fort Lee, NJ: Barricade, 1992.

MAFFESOLI, Michel. O tempo das tribos: o declínio do individualismo nas sociedades de massa. Rio de Janeiro: Forense Universitária, 1987.

MAGNANI, José Guilherme C. Os circuitos dos jovens urbanos, Tempo Social: Revista de Sociologia da USP, vol.17, p.2, 2005. p. 173-205.

MARCELINO, André F. \& BEINEKE, Viviane. Aprendizagens musicais informais em uma comunidade de prática: um estudo no grupo de maracatu Arrasta llha. Musica em Perspectiva, v.7, n.1, p.7-29, junho, 2014.

MARQUES, Isabel A. Ensino de dança hoje: textos e contextos. 6. ed. São Paulo: Cortez, 2011.

MARQUES, Isabel A. Linguagem da dança: arte e ensino. São Paulo: Digitexto, 2010 .

MARTÍN-BARBERO, Jesús. Dos meios às mediações: comunicação, cultura e hegemonia. 2. ed. Rio de Janeiro: UFRJ, 2003.

MARTÍN-BARBERO, Jesús. A mudança na percepção da juventude: sociabilidades, tecnicidades e subjetividades entre jovens. In: BORELLI, S.; FREIRE FILHO, J. (Org.). Culturas Juvenis no século XXI. São Paulo: EDUC, 2008. cap. 1, 9-32.

MARTINS, Guilherme Henrique B.; GRECA Juliana M. Potências híbridas: uma análise da cultura pop sul coreana como arte em campo ampliado na Indústria Cultural. O Mosaico - Revista de Pesquisa em Artes, Curitiba, n. 16, p. 1-240, jan./jun., 2018.

NECULA, Alexandra E. Restored behavior in K-pop performances: liminal experience, fantasy, the American influence, and how to overcome cultural barriers.

ANDREOLI, Giuliano Souza; FERNANDES, Braçi. O aprendizado informal da dança k-pop: juventude, transculturalidade e performances de gênero. Revista da FUNDARTE. Montenegro, p.01-21, ano 21, no -45 , junho de 2021 .

Disponível em: http://.seer.fundarte.rs.gov.br/index.php/revistadafundarte/index> 30 de junho de 2021. 


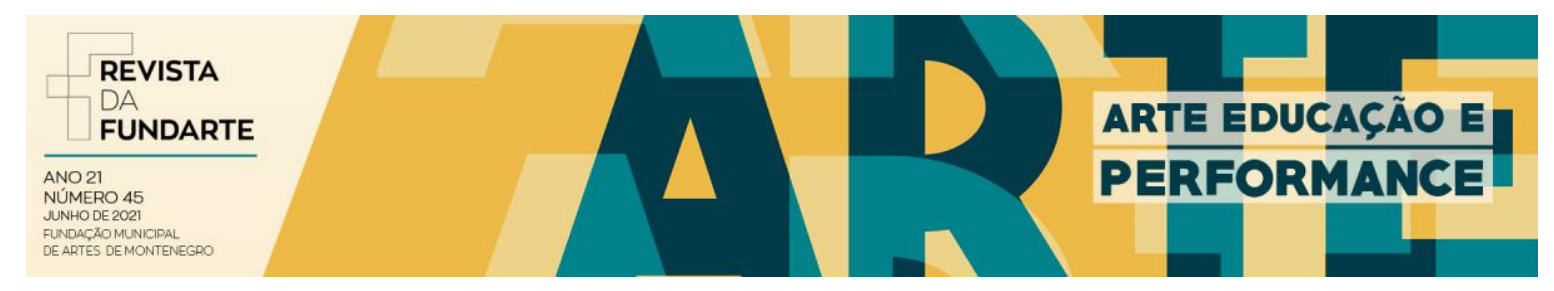

Thesis (Doctor degree). Sogang University Department of Mass Communications, Seoul, South Korea, 2017.

OROZCO GÓMEZ, Guillermo. "O telespectador frente à televisão: uma exploração do processo de recepção televisiva". Communicare. São Paulo, v. 5, n. 1, 2005, p. 27-42.

SANTANA, Aline Gomes. Juventude e identidades híbridas: reconversões culturais de jovens da cidade do Recife na cultura hallyu. Recife, 2018. 105 f. Dissertação (Mestrado em Consumo, Cotidiano e Desenvolvimento Social) - Universidade Federal Rural de Pernambuco, Recife, 2018.

SANTOS, Thiago Haruo. Idols em imagens e sons, fãs em re-ação: uma etnografia da prática musical do K-pop em São Paulo. Dissertação Mestrado, Faculdade de Filosofia, Letras e Ciências Humanas da faculdade de São Paulo, Departamento de Antropologia, São Paulo, 2016.

SCHECHNER, R. Pontos de contato entre o pensamento antropológico e o teatral. Cadernos de Campo, n. 20, p. 213-236, 2011.

SHIM, Doobo. Waxing the Korean Wave. Ari Working Paper, Singapura, n. 158, jun. 2011. Http://www.nus.ari.edu.sg/pub/wps.htm.

TOMAZZONI, Airton. Lições de dança no baile da pós-modernidade: corpos (des) governados na mídia. Tese (Doutorado), Faculdade de Educação, Universidade Federal do Rio Grande do Sul, 2009.

YOON, Kyong. Cultural Translation of K-Pop among Asian Canadian Fans. International Journal of Communication, n.11, 2017.

ANDREOLI, Giuliano Souza; FERNANDES, Braçi. O aprendizado informal da dança k-pop: juventude, transculturalidade e performances de gênero. Revista da FUNDARTE. Montenegro, p.01-21, ano 21, no 45, junho de 2021.

Disponível em: http://.seer.fundarte.rs.gov.br/index.php/revistadafundarte/index> 30 de junho de 2021. 